Cadernos de História, Belo Horizonte, v. 22, n. 37, Novembro de 2021

DOI: https://doi.org/10.5752/P.2237-8871.2021v22n37p314-333

\section{A Nova Rota Econômica \\ Do Futebol: MEgAeventos ESPORTIVOS E "O SONHO CHINÊS DAS TRÊS COPAS"}

Raul de Paiva Oliveira Castro Universidade Federal do Rio de Janeiro raulcastro13@hotmail.com

\title{
Resumo
}

Poucos estudos na historiografia dos esportes têm conferido a devida atenção ao crescimento econômico chinês e a sua relação com as práticas corporais institucionalizadas. Portanto, pretende-se contextualizar a trajetória dos esportes nos países socialistas e analisar a importância das Olimpíadas de 2008 para a China, a fim de entender melhor a recente ascensão do futebol no país. Logo, o objetivo central deste estudo foi elucidar o chamado "sonho chinês das três Copas do Mundo": voltar a disputar um Mundial, sediar esse megaevento esportivo e vencê-lo no futuro. Para cumprir tal proposta, foram utilizadas algumas reportagens da imprensa esportiva e documentos oficiais da Federação Internacional de Futebol Associação (FIFA), da Associação Chinesa de Futebol (CFA) e da República Popular da China (RPC), conferindo ênfase ao Plano de desenvolvimento do futebol chinês a médio e longo prazo (2016-2050). Observa-se como se deu a elaboração desse ousado planejamento estatal e de que maneira tem ocorrido uma forte aproximação entre os chineses e a entidade máxima do futebol mundial para realizá-lo. De acordo com o Plano, através do "socialismo com peculiaridades chinesas" surgirá o "futebol com características chinesas", fundamental para um maior intercâmbio político, econômico e cultural do país. Assim, a China encara com muita seriedade a realização desse projeto baseado nas estratégias encabeçadas pelo Estado, juntamente com a participação da iniciativa privada.

Palavras-chave: História econômica do futebol; Megaeventos esportivos; FIFA; Socialismo; China.

Recebido em 1 de outubro de 2020.

Aprovado em 27 de abril de 2021. 
Cadernos de História, Belo Horizonte, v. 22, n. 37, Novembro de 2021

DOI: https://doi.org/10.5752/P.2237-8871.2021v22n37p314-333

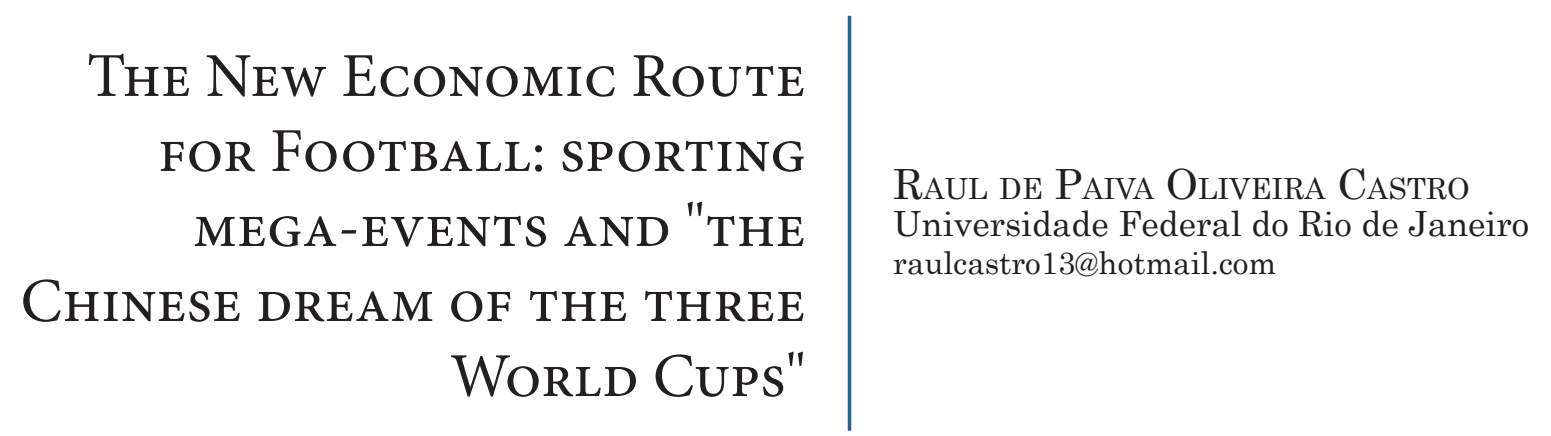

\begin{abstract}
There are few studies in the historiography of sports which have focused on the Chinese economic boom and its relationship with institutionalized bodily practices. Then, this paper aims to contextualize the path of sports in socialist countries and to analyze the importance of the 2008 Olympics for China, in order to comprehend the current rise of football in the country. Therefore, the main goal of this study is to elucidate the well-known: "Chinese dream of the three World Cups": to start to compete for a prize in a World Cup again and to host this sporting "mega-event". To fulfill the proposal, some news reports were used, from the sports press and official documents from the International Football Federation Association (FIFA), the Chinese Football Association (CFA) and the People's Republic of China (PRC), to give emphasis to the Chinese football development plan in the medium and long term (2016-2050). It can be noticed how this audacious government plan was prepared and how a strong relationship between the Chinese and the most important corporation of world football has taken place to carry it out. According to the Plan, "football with Chinese characteristics" will emerge through "socialism with Chinese peculiarities", which is fundamental for a greater political, economic and cultural exchange in the country. Therefore, China faces this project very seriously based on the strategies headed by the State together with the participation of the private sector.
\end{abstract}

Keywords: Economic history of football; Sports mega-events; FIFA; Socialism; China. 


\section{INTRODUÇÃo}

Este artigo é resultado de uma inquietação acerca do surpreendente desenvolvimento do futebol chinês nos últimos anos. Intenta-se, portanto, apresentar a imersão econômica agressiva da China, que confirma a tendência de mercantilização desse esporte: i) transações bilionárias de jogadores; ii) aumento de patrocinadores; iii) investimentos em categorias de base; iv) incremento da indústria esportiva etc. Para explicá-la, busca-se entender as razões desse súbito investimento asiático em um jogo que até então eles nunca haviam demonstrado grande interesse.

Ficou evidente a importância do presidente Xi Jinping, um entusiasta do futebol, que encabeçou o discurso do "sonho chinês". O mandatário fixou como obsessão a ideia de rejuvenescimento da nação através do futebol e estabeleceu três metas ousadas a realizarem-se em um curto período de tempo: participar, sediar e conquistar uma Copa do Mundo de futebol masculino da FIFA. Para tanto, foi redigido pelo governo chinês um Plano de desenvolvimento do futebol chinês a médio e longo prazo (2016-2050), que poderá ser visto ao final deste artigo. O Plano é dividido em metas de curto (2020), médio (2030) e longo prazo (2050).

Ademais, esta pesquisa se vale de variados tipos de fontes primárias e secundárias, tendo em vista o caráter recente dos acontecimentos. Dessa forma, foram utilizadas reportagens publicadas em português na imprensa esportiva ou disponíveis na internet (haja vista a dificuldade de acesso aos documentos originais escritos em mandarim). Pretendeu-se relacionar, também, os Documentos oficiais traduzidos da Federação Internacional de Futebol Associação (FIFA), da Associação Chinesa de Futebol (CFA) e da República Popular da China (RPC). A bibliografia secundária compreende primordialmente textos em português de história política e econômica do esporte, além de algumas poucas obras chinesas encontradas e traduzidas.

O presente artigo propõe-se a dialogar, sobretudo, com os mais recentes trabalhos oriundos da história econômica do esporte, cuja revisão bibliográfica ${ }^{1}$ foi primordial para elucidar inúmeras questões. Em que pesem os avanços nas pesquisas, é lícito pensar que o campo esportivo ainda pode permear outras áreas do conhecimento. Essa já é uma característica marcante da historiografia dos esportes e objetiva-se contribuir com esse debate. Nesse sentido, a forma pela qual o futebol tem sido mobilizado no âmbito das relações internacionais é vista pelos principais estudiosos da área como uma "das mais promissoras possibilidades de estudo da história do esporte”, (MELO et al.2013, p. 74).

É possível observar na sociedade - nos últimos anos - um momento de grandes transformações da geopolítica e economia mundiais, que geram implicações de ordem científica e tecnológica, dos blocos de poder, dos recursos humanos, dentre outras. Segundo Frank (1993), essas alterações seguem a noção de ciclos hegemônicos do sistema mundial, que podem ser elencados, cronologicamente, da seguinte maneira: ciclo holandês (séculos XVI e XVII); ciclo genovês (até o final do século XVII); ciclo inglês (século XVIII); ciclo estadunidense (a partir da Segunda Guerra Mundial).

Este último ciclo consolidou os EUA durante a Guerra Fria como a potência que

1 Em razão disso, foram listados alguns trabalhos de história econômica do esporte que motivaram e contribuíram de alguma forma com o desenvolvimento da nossa pesquisa: (CHARLE, 2012); (EDELMAN, 1993); (ROSS, 2014); (SANTOS, 2012); (SCOTT; WALKER; MISCALL, 2015); (SURDAN, 2015); (SZYMANSKI, 2015). 
impactava o sistema mundial e, em alguma medida, persiste até hoje, ainda que com certas dificuldades. Em outras palavras, os norte-americanos teriam estabelecido uma hegemonia de média duração, devido às suas condições econômicas favoráveis, bem como aos seus instrumentos políticos sofisticados e à sua elevada capacidade tecnológica e militar.

No entanto, a partir da Conferência de Bandung, em 1955, com o surgimento dos países não alinhados e o bloco do terceiro mundo, os norte-americanos começaram a enfrentar alguns desafios que culminariam no deslocamento recente da centralidade econômica do Ocidente para o Oriente, bem como no estreitamento da relação sul-sul. Ou seja, o mundo vem assistindo, pelo menos desde os últimos quinze anos, ao crescimento asiático (especialmente da China, através do seu modelo econômico capitalista com forte interferência do socialismo estatal) e às sucessivas crises do capitalismo estadunidense, que anunciam um momento de declínio do referido processo hegemônico norte-americano. Segundo Gunder Frank (2005):

\footnotetext{
Com o fim da guerra-fria em 1989 e o subsequente declínio da Rússia como um sério competidor imediato, assim como o declínio durante os anos de 1990 da fama do Japão como número um, duas outras regiões, Estados e poderes entraram na disputa. Um foi os Estados Unidos, cujos sucessos e expectativas pareciam ter declinado depois de 1970, mas que foram retomados nos anos de 1990; e mesmo assim como um Tigre de Papel. O outro foi a Ásia Oriental, apesar da sua crise após 1997, e especialmente a China - o Dragão de Fogo. (FRANK, 2005, p. 125).
}

A título de exemplo, dados publicados em 2014 pelo FMI têm colocado os chineses à frente dos norte-americanos no ranking das maiores economias mundiais (cálculo realizado pelo PIB, medido em dólar, ajustado ao poder da economia local e não em valores absolutos). Ademais, a projeção da inglesa PwC, para 2030, é de manutenção da China em primeiro lugar e, em 2050, da Índia, superando os EUA no segundo lugar.

Além disso, a tendência em longo prazo é dos países do chamado sul global ocuparem sete das dez primeiras posições no ranking e também ocorrer um deslocamento do Norte/Ocidente para o Sul/Oriente. Isso já pode ser constatado pelo fato de que os países desenvolvidos vêm estagnando ou decaindo economicamente, enquanto os emergentes asiáticos não param de crescer (China e Índia, cerca de 7\% ao ano, por exemplo). Prova disso é o acelerado desenvolvimento do mercado interno chinês, que impulsiona várias atividades, como se verá depois no caso do futebol:

\footnotetext{
As mudanças nos padrões de consumo ocorrem em todos os segmentos. Houve a introdução de novos hábitos alimentares (com efeitos significativos sobre o consumo de carnes e cereais), de novos bens industriais, tanto os da base tecnológica anterior (como automóveis) quanto os intensivos em TI (telefones celulares, computadores), e de novos serviços de apoio a essas transformações (telecomunicações, rodovias), como os decorrentes da elevação da renda pessoal, como turismo, alimentação fora da residência etc. (MEDEIROS, 2008, p. 94).
}

Nesse sentido, Frank (1993) aponta que é necessário ampliar-se a visão acerca do sistemamundo, rompendo com a concepção eurocêntrica e adotando uma visão "humanocentrista". Nesta, há uma reconstrução da história como um todo, que não esteja necessariamente ligada ao Ocidente, pensada através de redes e interações com sistemas. Este é um forte argumento para se compreender a emergência da Ásia contemporânea e a rapidez desse crescimento, tendo em vista que já existiam mecanismos internos que explicavam essa ascensão. 
É necessário, ainda, de acordo com Santos (1993), pensar esses territórios para além do espaço físico, mas também através das estruturas de organização do espaço mundial, como os blocos econômicos, por exemplo. Um desses novos agentes que vem atuando no campo esportivo por meio dos megaeventos é o bloco conhecido como BRICS.

Brasil, Rússia, Índia, China e África do Sul fazem parte de um acordo criado informalmente em 2006 e oficializado com a primeira cúpula em 2009 (ainda sem a África do Sul, que só entrou em 2011). Na intenção de coordenar reuniões e de construir uma agenda de cooperação multissetorial, o grupo se alargou e se solidificou ao longo dos anos. Com isso, seu crescente poderio de economias em desenvolvimento e o seu caráter de países grandes e populosos têm influenciado a geopolítica global por meio dos princípios de não interferência, igualdade e benefício mútuo.

Uma observação importante é que, em 2014, das dez maiores economias do mundo, cinco pertenciam aos países do BRICS. Nesses locais, percebe-se ainda uma gama de características em comum, tais como: desenvolvimento urbano recente; centros de modernização tecnológica; economias com forte interferência estatal; promoção de atividades culturais e esportivas; adoção de parcerias público/privadas; centros regionais de projeção dos interesses nacionais externamente etc.

Nota-se, então, que o cenário internacional está mudando mais rapidamente do que a nossa capacidade de entender essas dinâmicas e o esporte tem sido encarado como um poderoso instrumento de afirmação hegemônica. Não à toa, os países do BRICS têm sido escolhidos recentemente pela FIFA e pelo COI para sediar os principais megaeventos esportivos (Copa do Mundo e Jogos Olímpicos, especialmente). ${ }^{2}$ Conforme definição de Maricato (2014): os megaeventos esportivos ocorrem nas cidades, onde o processo de acumulação capitalista acontece de maneira acelerada, e nos últimos anos preferencialmente em países emergentes. Isso porque o enfoque dado historicamente pelo bloco às ações de infraestrutura (um dos pilares da Nova Rota da Seda chinesa, por exemplo), coadunou-se com as exigências de transformação urbanística, impostas pelos organizadores dos referidos torneios, na intenção de garantir conforto e segurança aos participantes. Para realizar os investimentos necessários, o Estado se coloca como o protagonista das obras e operações imobiliárias, juntamente com a parceria da iniciativa privada. Como resultado, cria-se um ambiente vigiado e espetacularizado, que servirá aos interesses do show midiático planetário.

Em que pese o seu referido caráter globalizante, os megaeventos esportivos também são momentos singulares nas trajetórias dos Estados nacionais, marcados por relações de dominação e protagonizados por agentes com interesses diversos. No âmbito futebolístico, é nítida uma interferência cada vez maior da FIFA, entidade supranacional, que dita as normas sem a menor preocupação em atingir diretamente a soberania dos países-sede. Os governos aceitam prontamente tais intromissões, "em benefício de determinados grupos", demonstrando enorme submissão a interesses externos que violam os direitos de ocupação dos espaços citadinos.

Entende-se, portanto, que por meio da divulgação de um sistema de regras racionais,

2 Estão listados a seguir, em ordem cronológica, os principais megaeventos esportivos dos países BRICS (20082018): 2008 - Olimpíadas de Verão (China); 2010 - Copa do Mundo (África do Sul); 2014 - Copa do Mundo (Brasil) e Olimpíadas de Inverno (Rússia); 2016 - Olimpíadas de Verão (Brasil); 2018 - Copa do Mundo (Rússia). 
pela defesa da tradição e pela existência da burocracia, a FIFA se resguarda institucionalmente perante os governos, as federações nacionais, seus patrocinadores e os torcedores. Logo,

\begin{abstract}
Sua governança de fato é complexa, pois ao mesmo tempo em que sua administração é majoritariamente exercida por agentes privados, garantindo um distanciamento de entes públicos, se faz necessário o exercício do lobby político para angariar financiamento público para a realização de seus eventos e desenvolvimento da sua organização (RODRIGUES, 2015, p. 73. Grifos nossos).
\end{abstract}

Por meio da chamada "governança global", ${ }^{3}$ a entidade se vale da estratégia conhecida como soft power, na qual molda as atitudes dos governos, influenciando-os e persuadindo-os a aprovar uma série de leis que favoreçam-nos. Para tal, a própria FIFA não emprega a força física, mas conta com a aquiescência dos comandos locais, utilizando táticas de convencimento. Assim, através da exploração simbólica e midiática de um dos maiores eventos esportivos do planeta, a Copa do Mundo, a entidade penetra nas legislações dos países-sede, adaptando-as a seu modo.

Acredita-se, então, que o recente interesse da China pelos megaeventos esportivos está inserido em um contexto mais amplo de aproximação da FIFA com os países do BRICS. É muito simbólico que África do Sul (2010), Brasil (2014) e Rússia (2018) tenham sido escolhidos como sedes do Mundial em sequência, por exemplo. Isto é, as economias emergentes vêm utilizando a Copa do Mundo e as Olimpíadas para mostrarem seu poderio, ainda que também sejam reveladas suas fraquezas.

Nas palavras de Rodrigues e Júnior (2018): "geopolítica e futebol se tornaram universos inseparáveis” (RODRIGUES; JÚNIOR, 2018, p. 29). Ao utilizar estratégias como o soft power (poder de influência) e o nation branding (nação como marca), o governo chinês, tão criticado por sua postura política fechada, visa mostrar uma imagem positiva do país perante a opinião pública internacional. Sendo assim, veremos que o futebol foi elencado como um dos principais motores desse empreendimento. Antes, porém, será proposta uma breve reflexão sobre o papel dos esportes em contextos socialistas.

\title{
A relaÇão do socialismo com os esportes de elite na China
}

Geralmente, quando se fala em história econômica dos esportes, logo se pensa na sua inserção dentro do sistema capitalista. Contudo, a experiência chinesa impele a olhar com cuidado para o seu caso específico. Certo é que, mesmo nos países socialistas, não houve uma ruptura com o chamado "projeto esportivo" (invenção do capitalismo inglês), de modo que o caráter competitivo permaneceu inalterado. Isso porque outras atividades cotidianas também se encaixaram nessa lógica de esportivização, que pressupõe o individualismo, o ranqueamento e a espetacularização.

\footnotetext{
3 "A partir de então, surge o cenário da governança global. Divergem os teóricos que a consideram um fenômeno empiricamente observável, daqueles que a subscrevem como um programa político, de sorte que os estudos sobre governança global costumam sobrepor ordens analíticas e normativas (ROSENEAU, 2000, p. 21-22). O conceito de poder nesse âmbito também não é consensual. Porém, a conceituação mais aceita é a de que o poder é a habilidade de obter os resultados desejados e, diretamente, a habilidade de influenciar os outros para obtê-los (NYE, 2004, p. 1-2), podendo ser por meio de coerção, indução e cooptação. A partir disso, Nye (2004) divide o poder em dois tipos: o hard power (coagir e induzir) e o soft power (cooptar). Esses conceitos, inicialmente, foram utilizados visando a sua utilização pela figura dos Estados, mas aplicam-se a diversos atores no cenário internacional” (PIZARRO, 2017, p. 3).
} 
Em vista disso, o historiador do esporte João Malaia Santos, segundo Edelman (1993), entende que se pode usar os mesmos teóricos do capitalismo para se estudar o desenvolvimento esportivo no socialismo, porém conferindo atenção a quatro particularidades deste último: (i) quem seriam as classes dominantes; (ii) como se comportaria a massa de consumidores; (iii) a falta de incentivo dada ao esporte-espetáculo nas escolas e (iv) os objetivos da mídia estatal e privada.

Em um dos poucos trabalhos acadêmicos que analisam historicamente a ascensão dos esportes em contextos socialistas, Robert Edelman (1993) aponta que nessas sociedades existiam várias possibilidades de práticas corporais institucionalizadas feitas para espectadores, apesar de todas as diferenças presentes dentro da extinta URSS. Interessante, neste sentido, a confrontação do tratamento dado às artes e ao futebol, no contexto autoritário do stalinismo:

\begin{abstract}
O estabelecimento, em 1934, da doutrina artística conhecida como "realismo socialista", restringia os tipos de filmes, arte, literatura, teatro e música que poderiam ser apresentados. Os homens e mulheres que faziam produtos da cultura de massa agora tinham que se conformar com uma censura cada vez mais estrita. Muitas carreiras foram encerradas e vidas arruinadas. Em comparação, o futebol de maneira muito mais consistente proporcionou uma performance relativamente honesta, que permitiu aos fãs emoção e liberação emocional. No meio do medo do período de expurgo, o futebol, diferentemente de muitas artes, foi capaz de reter o núcleo moral de sua atratividade humana. Isso não quer dizer que o futebol fosse um oásis dos apolíticos. O Partido sempre procurou usar um fenômeno tão popular para seus próprios fins. Pode-se até dizer que existe uma abordagem "realista socialista" do jogo que enfatizaria os valores oficiais que o Estado queria ensinar através do esporte. No entanto, as atrações do jogo eram tão grandes e sua espontaneidade fundamental, tão inevitável que o Estado nunca o mobilizou totalmente como uma ferramenta de domínio e controle. (EDELMAN, 1993, p. 62-63. Grifos nossos).
\end{abstract}

Percebe-se, então, que o stalinismo não foi capaz de manipular o futebol da mesma forma que fez com as outras artes, ainda que buscasse controlar as competições e os atletas. Certo é que o governo não conseguiu conter as torcidas e, quanto mais incerto o resultado do jogo, mais adeptos a modalidade conquistava. As competições locais chegaram a estabelecer um público considerável, mas foram os jogos internacionais que atraíram mais espectadores e uma atenção diferenciada da imprensa. No tocante à atuação dos veículos de comunicação, além dos anúncios das partidas, também promoviam críticas às atitudes do governo em relação ao desenvolvimento dos esportes, ainda que isso acontecesse dentro dos limites de um regime autoritário.

Assim, na União Soviética, mesmo tentando promover um esporte de participação, eles acabaram esbarrando no alto rendimento, principalmente para competir com os EUA, nos ditos torneios internacionais (conforme igualmente se verá mais à frente para o caso da China atual e sua obsessão pela Copa do Mundo). Pode-se dizer, então, que a partir da década de 1950, a URSS iniciou uma chamada "sovietização dos esportes", ainda que ali, essa prática não tenha sido encarada sob a ótica do tempo livre e da capacidade de lidar com os sonhos, como é o caso do modelo capitalista tradicional.

Nesse mesmo período, mais especificamente em 1949, a China tornava-se comunista, através de uma Revolução liderada por Mao Tsé-Tung. Com apoio dos camponeses, o Partido Comunista Chinês (PCC) organizou o Exército Popular de Libertação e tomou o poder, instaurando a República Popular da China (RPC). Nas palavras do líder: 
Na contradição em que a China se encontrou reduzida ao estado de semi colônia, o imperialismo ocupa a posição principal e oprime o povo chinês, enquanto a China, de país independente, transformou-se numa semi colônia. A situação, porém, há de modificar-se fatalmente. $\mathrm{Na}$ luta entre as duas partes, a força do povo chinês, força que cresce sob a direção do proletariado, há de transformar inevitavelmente a China de país semi colonial em país independente, enquanto que o imperialismo será derrubado, e a velha China transformada inevitavelmente numa China nova. (TSÉ-TUNG, 1975, p. 547).

Entretanto, já na década de 1970, as experiências maoistas levaram a sociedade chinesa a uma fase de aumento da pobreza, atraso econômico e terror ideológico. Após a morte de Tsé-Tung, em 1976, o PCC, liderado por Deng Xiao Ping, retomou o projeto das Quatro Modernizações, voltado aos seguintes setores: agricultura, indústria, ciência e tecnologia e defesa do país. Somado a isso, a China estabeleceu, no âmbito esportivo, uma chamada "estratégia olímpica". Assim, houve uma mudança da mentalidade esportiva (foco no esporte de elite e na competitividade) e surgiu a necessidade de recuperação da autoestima e do orgulho patriótico (reforçar a imagem de uma nação poderosa).

Dessa forma, com a bem-sucedida campanha da delegação chinesa nas Olimpíadas de 1984, em Los Angeles, o governo intensificou os investimentos nos esportes de alto rendimento, a fim de potencializar os resultados geopolíticos e sociais daquele evento. Contudo, o fracasso nos Jogos Olímpicos seguintes (Seul, 1988) suscitou questionamentos acerca da estratégia utilizada, notadamente direcionada à preferência pelos esportes de elite em detrimento dos de massa, fato esse que forçou o governo a admitir a necessidade de reformas.

Tendo em vista o que foi colocado acima, percebe-se que nos anos 1990 ainda existia um planejamento voltado para os esportes de elite, porém elaborado de maneira mais sustentável. Isso ocorreu devido a uma série de fatores: maior combinação com o setor educacional; melhoria nas estruturas físicas e administrativas; desenvolvimento dos esportes de massa (visava a uma política esportiva e de saúde pública) e aumento da participação do setor privado.

Logo, acompanha-se um desempenho crescente do país entre os Jogos Olímpicos de 1992 a 2000 (quando a China alcança o $3^{\circ}$ lugar geral). Isso contribuiu para o presidente Jiang Zemin reconhecer oficialmente o chamado Jugou Tizhi, isto é, deixar claro o valor político do sucesso esportivo ao afirmar que todo o país apoiava o esporte de elite. Nesse contexto de euforia, Pequim foi eleita em 2001 a sede das Olimpíadas de Verão de 2008, favorecendo ainda mais o investimento esportivo. ${ }^{4} \mathrm{O}$ grande intuito era superar a hegemonia dos EUA nos Jogos a serem disputados em casa, bem como aproveitar a oportunidade de passar uma nova visão sobre si mesma para o mundo:

\footnotetext{
Com investimento recorde de US\$ 43 bilhões, a China recebeu a 29a edição dos Jogos Olímpicos precisamente às 8 horas, 8 minutos e 8 segundos do dia 8 do mês 8 do ano de 2008 . Obviamente o culto ao número 8 não foi mero acaso. É um número que para a cultura chinesa significa sorte, prosperidade. De fato, a chegada das Olimpíadas internacionalizou a
}

4 Curioso notar, ainda, uma semelhança entre a China e o Brasil, nesse quesito. Em 2015, a delegação brasileira alcançou o $3^{\circ}$ lugar no ranking dos Jogos Pan-americanos, ficando atrás apenas dos EUA e do Canadá. Essa honrosa posição teve a ver com o fato de o Brasil ser o país latino-americano que mais investiu em esportes (dados da Forbes de 2015 apontaram que os gastos do governo giraram em torno de 840 milhões de dólares). Outra questão importante foi o recebimento dos principais megaeventos esportivos em um curto espaço de tempo (Copa do Mundo de 2014 e Olimpíadas de 2016). Em suma, percebe-se como essa "fórmula do sucesso" se repetiu nos dois países: gastar dinheiro com esportes próximo a período de megaeventos significa um retorno simbólico relevante para a nação. 
cidade, a dotando de melhor infraestrutura viária. Os Jogos anunciaram uma "nova China", moderna e tecnológica. ${ }^{5}$

Já na cerimônia de abertura, um megaevento simultaneamente esportivo e político, os chineses destacaram o seu papel no sistema mundial ao contarem a própria história como se fosse a da humanidade inteira. Ressaltaram-se, ali, três aspectos importantes: (i) o papel decisivo da tecnologia; (ii) o paralelo entre a tradição e a modernidade e (iii) a escrita da história propriamente dita. Para simbolizar tais elementos, salientou-se a contraposição entre a Velha e a Nova Rota da Seda.

O termo "Rota da Seda" foi criado no século XIX pelo geógrafo alemão Ferdinand Von Richthofen e designava os antigos laços comerciais entre a Europa e a Ásia. Em 2013, a expressão foi ressignificada por Xi Jinping, segundo o qual era preciso construir "Um Cinturão, Uma Rota". Esse ambicioso projeto econômico está ligado sobretudo ao intercâmbio na área de infraestrutura, valorizando-se as semelhanças ao invés das diferenças e o compartilhamento de benefícios mútuos. Na tradição cultural chinesa, somente por meio da integração harmoniosa e pacífica entre as nações é possível alcançar a prosperidade material e espiritual. Assim, o "Cinturão Econômico da Rota da Seda do século XXI" visa abrir um novo capítulo da história mundial em termos geopolíticos, econômicos e culturais. Trata-se, pois, de uma oportunidade para a China estabelecer o protagonismo no âmbito das relações internacionais, através de uma governança global compartilhada (soft power). (XINHUA, 2016a).

Em um dos vários discursos do presidente Xi Jinping a esse respeito, ele comenta sobre as diretrizes do projeto:

\begin{abstract}
Devemos perseverar no pensamento estratégico de que o desenvolvimento é o que conta e, na consideração da construção econômica como tarefa central, realizar a construção socialista nos campos da civilização econômica, política, cultural, social e ecológica, aprofundar a reforma e abertura, e promover o desenvolvimento científico, estabelecendo constantemente uma sólida base material e cultural para a materialização do sonho chinês. (XI JINPING, 2015, p. 50).
\end{abstract}

Em um contexto internacional marcado pela guerra ao terrorismo, iniciado após os ataques de 11 de setembro de 2001, nos EUA, os chineses reforçaram a questão da paz ao longo de vários momentos da cerimônia. Paralelamente, ostentaram poder, força e riqueza, demonstrando para o mundo a sua grandiosa visão imperial de civilização e propagandeando o seu pioneirismo nas tecnologias do futuro. De acordo com Uvinha (2009), responderam aos críticos da opinião pública internacional, que sempre colocaram o autoritarismo político e os problemas ambientais do país como entraves para a China receber os Jogos em outras ocasiões. Dito de outra forma, os chineses levaram o planejamento das Olimpíadas a sério e investiram pesado para que tudo saísse conforme o previsto (UVINHA, 2009).

É preciso ressaltar que, para além da importância de conquistar títulos e medalhas, o desenvolvimento do esporte chinês também tem sido enxergado como um motor da reforma política, ao alterar substancialmente o estilo de vida dos seus habitantes. Em reportagem de agosto de 2016, intitulada: "Pessoas em primeiro lugar: o desenvolvimento do esporte

5 Cf. Globo Esporte, 2018. Legado esquecido: dez anos depois de Pequim 2008, instalações olímpicas estão abandonadas. 
na China como motor da reforma", ${ }^{6}$ nota-se como essa responsabilidade estatal tem sido desempenhada com muita seriedade.

Desde que o país voltou a disputar as Olimpíadas, em 1984, o orgulho chinês nas variadas conquistas esportivas teve o seu ápice nos Jogos Olímpicos e Paraolímpicos de Verão em Pequim (2008), quando o país-sede liderou o quadro de medalhas em ambos os torneios. ${ }^{7}$ Aliás, nas competições para deficientes, a China tem se tornado uma potência graças aos investimentos estatais, bem como a propaganda em torno da sua valorização, cujo resultado tem sido um maior recrutamento de atletas e envolvimento do público.

Outrossim, a oportunidade de sediar esse megaevento foi encarada pelo governo como uma "ferramenta educacional", tendo em vista o histórico preconceituoso em relação aos deficientes no país. De acordo com Guan Zhixun, professor da Faculdade de Esportes e Saúde da Zhejiang Normal University: "Isso foi uma novidade. O país não experimentou esse movimento antes, como países do Ocidente. A cultura tradicional da China via os deficientes como pessoas inúteis. Agora, os chineses começam a vê-los como pessoas que enfrentam desafios" ${ }^{8}$

Nesse sentido, foi de suma importância uma instituição que nasceu pequena, visto que o movimento de pessoas com deficiência no país é recente, mas em pouco tempo desenvolveu uma estrutura expressiva (considerando o tamanho da China e o grande número de deficientes):

\begin{abstract}
A Federação Chinesa de Pessoas com Deficiência, instituição semigovernamental, foi fundada em 1998 pelo filho de Deng Xiaoping (ex-líder chinês), Deng Pufang, que ficou paraplégico após ser torturado durante a Revolução Cultural, movimento sociopolítico lançado para preservar a "verdadeira" ideologia comunista. Segundo Guan Zhixun, a instituição teve papel central na melhora do desempenho da China na Paraolimpíada. A federação tem atuação em todo país, com braços regionais e locais. Por meio dela, o governo investe no atendimento às pessoas com deficiência, inclusive no treinamento de atletas e treinadores paraolímpicos. Dados de 2014 apresentados pela federação, por exemplo, mostram que naquele ano o país realizou 20 competições nacionais de esportes paraolímpicos, com a participação de mais de 6 mil deficientes. Já no nível municipal, foram promovidos 5.544 eventos, com participação de 694 mil pessoas. ${ }^{9}$
\end{abstract}

Após o auge do Jugou Tizhi, com a histórica campanha chinesa nas Olimpíadas e Paraolimpíadas de 2008, esperava-se que o esporte perdesse a sua importância política, afinal de contas, o principal objetivo já havia sido alcançado. Entretanto, o que se viu foi a continuidade e um reforço desse sistema, na intenção de restaurar a "grande civilização chinesa”. Uma prova disso é o atual interesse do presidente Xi Jinping em utilizar o futebol como ferramenta para atrair investimentos e projetar o país externamente.

Além do "sonho das três Copas", outro megaevento esportivo já está garantido na China: os Jogos Olímpicos de Inverno de 2022. Dessa forma, Pequim se tornará a única

6 Cf. XINHUA PORTUGUÊS, 2016b. Pessoas em primeiro lugar: o desenvolvimento do esporte na China como motor da reforma (3).

7 Resultados da China no quadro de medalhas dos Jogos Olímpicos de Verão (anos 2000): 3o lugar em Sydney/2000; 20 lugar em Atenas/2004; $1^{\circ}$ lugar em Pequim/2008; $2^{\circ}$ lugar em Londres/2012; $3^{\circ}$ lugar em Rio/2016. Resultados da China no quadro de medalhas dos Jogos Paraolímpicos de Verão (anos 2000): $6^{\circ}$ lugar em Sydney/2000; $1^{\circ}$ lugar em Atenas/2004; 10 lugar em Pequim/2008; $1^{\circ}$ lugar em Londres/2012; 10 lugar em Rio/2016. [Grifos nossos].

8 Cf. BRITISH BROADCASTING CORPORATION, 2016. Como a China se tornou a maior potência paraolímpica.

9 Cf. BRITISH BROADCASTING CORPORATION, 2016. Como a China se tornou a maior potência paraolímpica. 
cidade no mundo a receber as edições de verão e inverno das Olimpíadas. E esse crescente interesse pelos esportes de inverno vai além da busca por medalhas. Segundo Liu Peng, diretor da Administração Geral de Esportes da China, ao se aproximar das grandes massas, "o desenvolvimento dos esportes de inverno na China pode melhorar a condição física e o estilo de vida da população", ${ }^{10}$ isto é, servir ao povo chinês.

Somado a isso, pode alavancar a indústria de esportes de inverno direcionada a cidadãos comuns, conforme um exemplo dado por Cui Ping: "Como os chineses estão ficando mais ricos, mais e mais pessoas vão esquiar" ${ }^{11}$. Em suma, de acordo com os dados apresentados pela reportagem a seguir, podemos concluir que:

\footnotetext{
"O ano de 2008 foi um marco, pois os Jogos Olímpicos deram à população uma nova visão sobre esporte", disse Song Hongfei, do grupo de marketing esportivo Wisdom Sports Group. Ele afirmou que as medalhas de ouro para grandes estrelas são ótimas, mas que o esporte também serve para ajudar as pessoas não atletas a se manter saudáveis e a se divertir. A companhia de Song organiza várias maratonas na China, onde as corridas entraram na moda. Mais de 1,5 milhão de pessoas participaram de mais de 130 delas em 2015. Fisiculturismo e outros esportes também estão em alta. Se as expectativas se confirmarem, 435 milhões de chineses praticarão esportes regularmente em 2020. Um plano publicado pelo gabinete chinês em 2014 estabeleceu como meta a produção industrial superar 5 trilhões de yuans por ano até 2025. O começo do plano tem sido animador. O setor de serviço da China, que inclui o esporte, respondeu por $56,9 \%$ do crescimento de $6,7 \%$ que o PIB apresentou no primeiro semestre de 2016. A China está se aproximando da meta de se tornar uma sociedade "Xiao Kang", que significa "rica", sendo que o significado literal de "kang" é "saudável". ${ }^{12}$
}

Tudo começou pela educação, através do incentivo governamental ao esporte nas escolas. Preocupados com a condição física dos seus filhos, os pais apoiam tais medidas por entenderem que farão bem à saúde dos jovens. Ao passo que vem se tornando um hábito cultural, o esporte tem ganhado posição de destaque nos estudos universitários. Além disso, a China é o país que mais tem investido em ciência e em tecnologia, especialmente nas áreas de exatas e de engenharia. A tendência é aumentar, já que o governo entende ser fundamental estar à frente nas pesquisas para ditar as regras na geopolítica internacional.

Após essa breve explanação sobre a recente ascensão dos esportes na China, será abordada, no próximo tópico, uma modalidade específica, o futebol. Sendo assim, nosso objetivo é mostrar como o projeto esportivo chinês encontrou nesse jogo uma possibilidade de desenvolvimento econômico ainda maior, alcançando cifras impensáveis. Inicialmente, será apresentada a profissionalização do jogo no país e, em seguida, algumas explicações a respeito da agressiva participação financeira dos chineses na conjuntura atual do esporte bretão.

\section{O DESENVOLVIMENTO DO FUTEBOL COM PECULIARIDADES CHINESAS}

A princípio, vale a pena dizer que durante aquele referido contexto de reforma dos esportes de elite, no início dos anos 1990, ocorreu simultaneamente a profissionalização do futebol na China. Conforme se vê em Rodrigues e Júnior (2018), pode-se elencar três fatores que contribuíram decisivamente nesse processo: (i) a criação de uma liga nacional (Super Liga

10 Cf. XINHUA PORTUGUES, 2016b. Pessoas em primeiro lugar: o desenvolvimento do esporte na China como motor da reforma (3).

11 Ibid.

12 Ibid. 
Chinesa) semelhante às europeias; (ii) o protagonismo da iniciativa privada na administração dos clubes e na comercialização do esporte e (iii) a liderança da Associação Chinesa de Futebol (CFA) na organização do campeonato local, bem como no incentivo às categorias de base.

Nos primórdios de sua existência, a Série A da Super Liga Chinesa conseguiu um relativo sucesso financeiro e de público. Por exemplo, o campeonato obteve uma boa média de 20 mil pessoas por partida no seu primeiro ano. Ademais, as rendas empenhadas com bilheteria, publicidade, patrocinadores, direitos de transmissão etc., permitiram aos clubes uma relativa autonomia financeira. Ainda segundo Rodrigues e Júnior (2018), em apenas quatro anos, a China surpreendentemente saltou de 20 times profissionais para um total de 360 , além de 1 mil jogadores registrados para uma quantia de $30 \mathrm{mil}$.

Se, por um lado, o futebol chinês alavancou nos anos 1990, por outro, alguns problemas internos e o desempenho ruim no âmbito internacional contribuíram para uma crise do futebol profissional. A título de exemplo, o selecionado nacional não se classificou para as Olimpíadas de 1996 e 2000, como também fracassou nas competições asiáticas e eliminatórias para a Copa do Mundo da FIFA de 1998.

Diante da insatisfação dos torcedores perante a baixa qualidade técnica do campeonato local, aumentaram-se as críticas quanto aos enormes salários dos jogadores e apontaram-se diversas falhas da Liga na condução das categorias de base. Além disso, no início dos anos 2000, começaram a eclodir escândalos de corrupção em todos os níveis de comando, tendo por consequência, uma perda significativa do valor de mercado, credibilidade e relevância da Super Liga Chinesa.

Somente em 2011 é que as ações de combate à corrupção começaram a surtir efeito, resultando em prisões de atletas, árbitros e até mesmo do vice-presidente da CFA, todos partícipes em algum grau dos esquemas ilegais de apostas e vendas de partidas. Após essas medidas punitivas, lideradas pelo governo chinês, a Super Liga começou a ganhar visibilidade internacional e o Guangzhou Evergrande venceu dois campeonatos continentais da Ásia. Portanto, aumentaram-se substancialmente os investimentos dos clubes e o valor de mercado dos elencos.

Outro dado importante é que, de acordo com Rodrigues e Júnior (2018), em 2017, a Super Liga Chinesa superou a tradicional La Liga Espanhola nos valores de transferências de jogadores (550 milhões de euros contra 508 milhões de euros, respectivamente). Dentre as maiores contratações de atletas, os brasileiros têm sido, recorrentemente, alvo preferencial dos chineses, por ainda serem considerados um celeiro de craques:

\begin{abstract}
Muito dinheiro e jogadores brasileiros. A soma desses dois fatores é a estratégia usada pela China para evoluir o seu futebol desde 2013. É o que revela Kimberly Morris, chefe de Integridade e Compliance do Fifa TMS, o sistema de transferências usado por clubes de todo o mundo. Dados divulgados por ela indicam que os chineses gastaram 447 milhões de dólares só em atletas brasileiros desde 2013. Isso representa quase metade de tudo que foi gasto pelos times da China no período, que foi 997,8 milhões de dólares. ${ }^{13}$
\end{abstract}

O gráfico a seguir apresenta uma comparação entre o Brasil (coluna amarela) e a China (coluna cinza), e considera qualquer movimentação no mercado do futebol entre 2013 e 2017. À esquerda, há o número de transferências separado entre chegadas (acima) e saídas (abaixo).

13 Cf. GLOBO ESPORTE, 2017. China gastou 447 milhões de dólares só com jogadores brasileiros em cinco anos. 
À direita, há a quantia em dinheiro (milhões de dólares): em cima, o total gasto e, em baixo, o montante recebido.

Figura 1 - Comparação entre Brasil e China

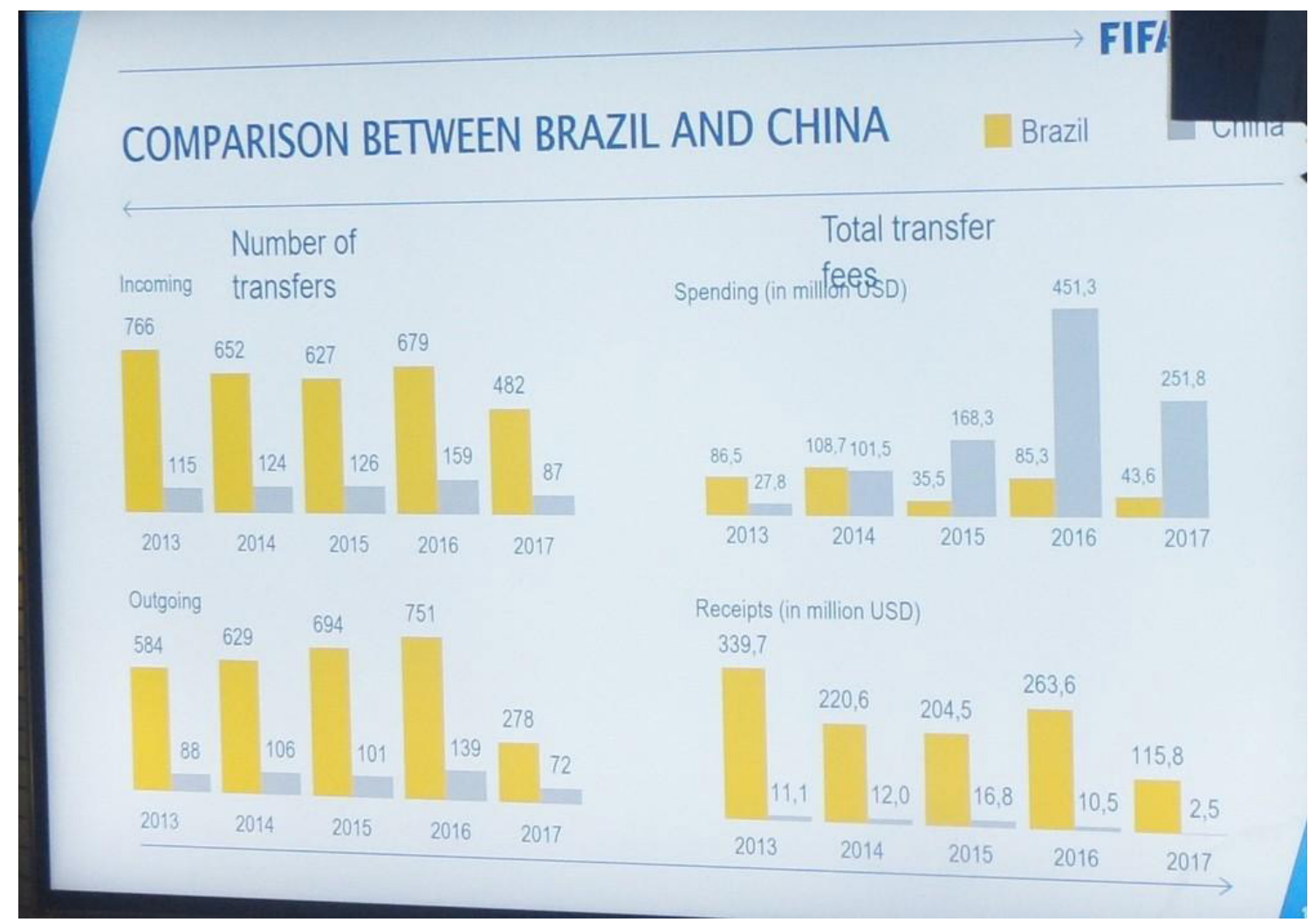

Fonte: https://globoesporte.globo.com/futebol/futebol-internacional/noticia/china-gastou 447-milhoes-de-dolares-so-com-jogadores-brasileiros-em-cinco-anos.ghtml.

Após analisar os dados estatísticos acima, alguns apontamentos merecem destaque: (i) há uma relativa tendência de estabilidade das chegadas de atletas nos dois países, mas com o Brasil sempre obtendo números absolutos bem maiores que os da China; (ii) entre 2013 e 2016 observa-se uma crescente saída de jogadores brasileiros, até que em 2017 ocorre uma queda abrupta após o lançamento do Plano; (iii) o mercado chinês gastou vultosa quantia de dinheiro no período, sobretudo em 2016, porém não arrecadou tanto quanto o brasileiro. Como efeito, tamanha quantidade de recursos investidos no futebol também dilatou as dívidas dos clubes, fato que recentemente tem sido motivo de preocupação, tanto para a CFA, quanto para o governo. Dito de outra forma, os chineses gastam tal qual os europeus, porém sua arrecadação é muito menor, o que no futuro pode gerar uma perigosa bolha na economia.

$\mathrm{Na}$ intenção de conter esses gastos exorbitantes dos clubes chineses, em 2016, foi lançado pelo presidente Xi Jinping o Plano de desenvolvimento do futebol chinês a médio e longo prazo (2016-2050), ${ }^{14}$ sobre o qual se debruçará adiante. Em termos de formatação, o documento conta com quatorze páginas e está dividido em cinco grandes seções: (i) Fundação de desenvolvimento; (ii) A ideia geral; (iii) Objetivos de desenvolvimento; (iv) A principal tarefa e (v) Políticas de apoio e medidas de salvaguarda. Cada uma dessas partes está dividida em tópicos que tratam mais detidamente sobre os assuntos, além de algumas ditas "Caixas", que funcionam como subtópicos para ilustrar a relação do $13^{\circ}$ Plano Quinquenal do Partido 
Comunista Chinês com os esportes.

Em linhas gerais, o Plano estabelece o "sonho das três Copas": voltar a disputar, sediar e ganhar o Mundial até 2050. Sabe-se que, desportivamente, são metas ousadas, pois a China participou, até hoje, apenas de uma Copa do Mundo (em 2002, na Coreia do Sul e no Japão, perdeu os três jogos e não marcou nenhum gol). Além do fato de que a sua seleção não consegue ser uma potência nem mesmo no continente asiático. Porém, não se pode duvidar da capacidade de um país que leva seus planejamentos a sério, como foi visto na organização das Olimpíadas de 2008.

No Plano de desenvolvimento do futebol chinês a médio e longo prazo (2016-2050), são apresentadas, detalhadamente, as atribuições da iniciativa pública e privada, capazes de garantir que esses sonhos se concretizem. Dois elementos importantes elencados no texto dizem respeito às categorias de base e ao desenvolvimento do esporte de massa. Dentre as suas principais medidas, destacam-se: (i) implementação do futebol no currículo do ensino médio; (ii) construção de campos de futebol e (iii) incentivo aos jogadores nativos em detrimento de contratações estrangeiras. Em termos estatísticos, é lícito confirmar isso quando o Plano ambiciona a criação de 20 mil escolas e 70 mil campos de futebol, totalizando um número de 30 a 50 milhões de jovens se dedicando regularmente à prática do esporte até 2020.

É interessante salientar, ainda, a estreita relação entre o Plano e a organização da Super Liga Chinesa. Regulamentou-se a política de taxação das transferências, o controle do número de jogadores estrangeiros e o incentivo aos atletas abaixo dos 23 anos dentro da competição. Nele, estava estabelecido que as compras de jogadores acima do teto de 5,9 milhões de euros passariam a ser taxadas em 100\% pela Associação Chinesa de Futebol. De imediato, isso acarretou uma queda acentuada de $68 \%$ no valor das transferências. Outra importante medida tomada foi a criação de um fundo de apoio às categorias de base do futebol chinês, projetando menos gastos e mais receitas com atletas no futuro.

A intenção chinesa com o Plano é desenvolver vigorosamente a indústria de serviços do futebol. Basta se verificar que o país pretende criar um mercado esportivo de aproximadamente 813 bilhões de dólares até 2025, sendo que o futebol representaria 43\% desse total. Primeiramente, tendo melhores jogadores na Super Liga, as partidas de alto nível promoveriam o crescimento das transmissões televisivas, da publicidade e dos serviços de rede. Isso abriria caminho para o entretenimento de massa, estimulando internamente a produção, a circulação e o consumo dos suprimentos de futebol: roupas, lembranças, bilhetes de loteria, equipamentos, instalações, e-sports etc. Por fim, setores como agenciamento, treinamento, pesquisa, operacional e financeiro também seriam impulsionados nos bastidores desse mercado futebolístico.

Indubitavelmente, o presidente Xi Jinping é um entusiasta do futebol, mas devemos entender que a escolha desse esporte não se deu de maneira arbitrária ou despretensiosa. Por se tratar do jogo mais popular do planeta, a China busca aliar o futebol à sua estratégia de acumulação, usando o chamado soft power (poder de influência). Em outras palavras,

O exercício do soft power no esporte não ocorre apenas na organização dos megaeventos esportivos. Ao aliar os mecanismos de soft power com as técnicas de marketing para criar uma marca ("branding") de uma nação e assim mudar a visão da opinião pública internacional - "nation branding". O conceito de "nation branding" também é encontrado em Peter Van Ham, mas com outra denominação. Em artigo na Foreign Affairs, Van Ham escreveu sobre

"A ascensão do Estado marca" ("brand state") e diz que "brand state" compreenderia a ideia 
que o mundo exterior teria a respeito de um país em particular. Para Van Ham, há marcas que devido à sua imagem e reputação terminam simbolizando seus países no mundo. (RODRIGUES; JÚNIOR, 2018, p. 36).

Trata-se, pois, de um objetivo econômico e diplomático que se pauta numa intensa relação entre passado, presente e futuro. Ou seja, baseada em experiências históricas anteriores, a China também enxerga possíveis alianças comerciais (com o Irã, por exemplo, um importante parceiro para a concretização da Nova Rota da Seda) que podem ser forjadas por meio dos esportes. Além do mais, sediar e conquistar uma Copa do Mundo pode ser uma oportunidade única para reafirmar o lugar da China como uma potência global e atrair a atenção de novos investidores, comerciantes e turistas estrangeiros.

Vale a pena dizer, ainda, que todos os esforços do governo chinês foram realizados de acordo com o novo padrão de acumulação definido pela cadeia global de valor. Esta amplifica as atividades e os serviços que incrementam maior valor na produção, a saber: marketing, branding e direitos televisivos. Por exemplo, muitos times da Super Liga Chinesa são vinculados a empresas produtivas do país e o futebol auxilia na valorização das suas marcas e projeção desses clubes a nível internacional.

Outra evidente demonstração do envolvimento do capital chinês no mercado futebolístico atual tem sido o grande investimento da iniciativa privada em clubes estrangeiros, principalmente a partir de 2015. Dentre os motivos mais relevantes para tais empreendimentos, observa-se uma enorme rentabilidade financeira, a formação de um knowhow e o avanço das categorias de base. Portanto, essa referida compra de times internacionais evidencia que as empresas chinesas estão cada vez mais buscando fontes alternativas de renda (serviços, tecnologia, inovação etc.), de sorte que o futebol possui um pouco de cada uma dessas variáveis.

Percebem-se, ainda, outras características desse modelo acumulativo trazido pelo futebol: o crescimento da renda per capita e do consumo doméstico. Eles não se configuram como fatores determinantes do processo em si, mas são importantes para criar condições favoráveis aos investimentos. Para tanto, é preciso desenvolver uma "cultura do futebol", na qual as famílias tenham renda suficiente para consumir esse bem de luxo (classificado economicamente desta forma por não ser indispensável à sobrevivência).

Contudo, essa missão é árdua e complexa, na medida em que a superação da força europeia no esporte exige muito mais do que simplesmente investimento e planejamento. É necessário que o governo chinês consiga propagandear o futebol como um objetivo coletivo e nacional para, definitivamente, inseri-lo na cultura local. À vista disso, o Plano estabelece "um conceito de futebol saudável, feliz e agressivo" relacionado ao "espírito esportivo de trabalho duro, progresso, unidade e cooperação"; aspectos tão característicos da sociedade chinesa. Dessa forma, pretende-se difundir o papel positivo e civilizatório do futebol, por meio do respeito às regras do jogo, a fim de contribuir para o bem da coletividade, aprimorando o sentimento de honra e orgulho nacional. A respeito da necessidade de se estabelecer uma hegemonia cultural no país, o presidente Xi Jinping proferiu o seguinte discurso: 


\begin{abstract}
da luta dos dois centenários ${ }^{15}$ e o sonho chinês da grande revitalização da nação chinesa. Devemos levar a cabo a cultura socialista avançada, aprofundar a reforma do regime cultural, promover o grande desenvolvimento e o florescimento da cultura socialista, promover o vigor criativo cultural de toda a nação, promover a prosperidade integral das atividades culturais e o desenvolvimento acelerado da indústria cultural, enriquecendo constantemente o mundo espiritual do povo, acentuando incessantemente sua força espiritual e promovendo continuamente a força integral da cultura e sua competitividade, para marchar incansavelmente em direção à meta de tornar nosso país um forte país socialista na cultura (XI JINPING, 2015, p. 201).
\end{abstract}

É sabido que, desenvolver satisfatoriamente a hegemonia cultural de um esporte de massa em um país, como é o caso do basquete nos EUA, ou o futebol no Brasil, exige tempo e uma série de outros fatores que muitas vezes estão longe de serem previsíveis. Observando a própria história da criação da Liga dentro da China, vê-se um aumento da popularidade do futebol, por meio da presença maciça de torcedores nos estádios, ainda que tenha ocorrido uma série de turbulências para a competição se consolidar. E essas dificuldades são vistas até hoje, por exemplo, como uma certa resistência de as crianças chinesas praticarem o esporte por considerarem chato ou muito profissional.

Logo, torna-se ainda mais relevante verificar essa aplicação volumosa de dinheiro dos clubes na popularização do futebol, a fim de que a Super Liga tenha qualidade e consiga competir com os tradicionais times europeus. $O$ problema é que, se não ocorrer uma promoção dos atletas de base chineses, ficarão reféns das compras de jogadores estrangeiros. Por essa razão, a atuação regulatória do governo, através do Plano, mostra-se fundamental nos objetivos a longo prazo, à proporção que condiciona as contratações milionárias ao investimento na formação das crianças locais.

Por fim, é relevante ressaltar, ainda, a estreita relação entre a China e FIFA, que vem se intensificando nos últimos anos. Politicamente, o presidente da Confederação Asiática de Futebol é o chinês Jilong Zhang e o secretário-geral da CFA tornou-se um dos membros do Conselho da FIFA, demonstrando a força do país nas decisões da entidade máxima do futebol. Economicamente, as empresas chinesas representam o maior volume de patrocínios das competições organizadas pela FIFA, tendo sido responsáveis por cerca de $37 \%$ do montante no Mundial da Rússia, em 2018. ${ }^{16}$ Desportivamente, a China candidatou-se como a sede do Mundial de Clubes em 2021, o primeiro a ser disputado no formato quadrienal, o que indica uma provável futura recepção da sonhada Copa do Mundo.

\title{
CONSIDERAÇõES FINAIS
}

É sabido que a China tem intensificado, nos últimos anos, sua relação com os esportes, sobretudo a partir do sucesso na gestão do megaevento em 2008. Desde as Olimpíadas de Verão de Pequim, quando pela primeira vez o país terminou à frente dos EUA no quadro geral de medalhas, passando pela candidatura às Olimpíadas de Inverno de 2022, investiu grandes quantias em dinheiro para entrar definitivamente no rol das nações esportivas.

15 Os dois centenários referem-se, respectivamente, ao centenário de fundação do Partido Comunista Chinês, em 2021, e ao centenário de fundação da República Popular da China, em 2049.

16 “As chinesas Wanda, Hisense, Vivo, Mengniu, Yadea, Luci e Diking foram sete das 19 patrocinadoras da Copa 2018. Juntas, as sete empresas chinesas representam um aporte financeiro de US\$ 835 milhões para a competição da FIFA.

Quantia que contribuiu para que o faturamento global da competição atingisse os valores de US\$ 6,12 bilhões e, assim, superasse em US\$ 500 milhões, o arrecadado em 2014” (RODRIGUES; JÚNIOR, 2018, p. 44). 
Além disso, a influência global do futebol chinês tem sido vista, neste início de século, graças às compras bilionárias de times, de jogadores e de técnicos do mundo todo, impulsionada pelo crescimento econômico do país, que incentiva a participação do setor privado. Entretanto, pode ser visto que tal prática tende a diminuir por causa do início da cobrança de impostos sobre aquelas transações, o que não acontecia anteriormente.

É possível constatar, portanto, que o grande passo esportivo do governo, dado pósOlimpíadas, foi a elaboração do Plano de desenvolvimento do futebol chinês a médio e longo prazo (2016-2050), idealizado por Xi Jinping e que recebeu o aval do Comitê para a Reforma. A estratégia chinesa é influenciar a população local aficionada por futebol, assim como o resto do mundo, através das suas conquistas nos gramados. Na visão dos idealizadores desse projeto, não é aceitável que a $2^{\text {a }}$ maior economia mundial seja apenas a $82^{\text {a }}$ força no esporte mais popular de todos. Isso porque, apesar dos reconhecidos avanços, tanto os clubes quanto a seleção chinesa continuam sendo decepcionantes em termos de desempenho nas principais competições que disputam.

Em suma, intentou-se destacar, neste artigo, a trajetória dos esportes em países socialistas, a fim de evidenciar os esforços do governo chinês em promover tamanha estratégia futebolística em médio e longo prazo. Isso foi feito no sentido de contribuir para elucidar o atual cenário geopolítico e econômico do país, destacando o papel que os esportes desempenham nesse processo e, finalmente, atentando para o caso do futebol propriamente dito. 


\section{REFERÊNCIAS BIBLIOGRÁFICAS}

BRASIL. Ministério das Relações Exteriores. In: Gov. br. Disponível em: http://www.itamaraty. gov.br/pt-BR/politica-externa/mecanismos-inter-regionais/3672-brics. Acesso em: 12 set. 2019.

BRAUDEL, Fernand. História e ciências sociais: a longa duração. In: Escritos sobre a história (2a ed.). São Paulo: Perspectiva, 2005.

BRITISH BROADCASTING CORPORATION. Como a China se tornou a maior potência paraolímpica. Disponível em: https://www.bbc.com/portuguese/brasil-37395777. Acesso em: 10 dez. 2019.

BRITISH BROADCASTING CORPORATION. Disponível em: http://portuguese.xinhuanet. com/2016-08/08/c_135561074.htm. Acesso em: 03 dez. 2019.

BRUCKMANN, Monica. Recursos naturales y la geopolítica de la integración sudamericana. Perúmundo: Lima, 2012.

CHARLE, Christophe. A Gênese da Sociedade do Espetáculo: teatro em Paris, Londres, Berlim e Viena. In: Cia. das Letras. São Paulo, 2012.

CHINESE FOOTBALL ASSOCIATION. In: The CFA. Disponível em: http://www.thecfa.cn/ gzzg/index.html. Acesso em 13 nov. 2019.

DAMO, Arlei Sander. O simbólico e o econômico no futebol de espetáculo: as estratégias da FIFA para tornar as Copas lucrativas a partir de uma interpretação antropológica. Razón y Palabra, Instituto Tecnológico y de Estudios Superiores de Monterrey (México), v. 14, n. 69, jul./ ago. 2009.

EDELMAN, Robert. A history of spectator sport in the URSS. In: Serious fun. Nova Iorque: Oxford University Press, 1993.

FEDERAÇÃO CHINESA DE FUTEBOL. Disponível: https://es.fifa.com/associations/association/ chn/news/. Acesso em: 03 out. 2021.

FORBES. Brasil é país latino-americano que mais investe em esportes. Disponível em: https://forbes.com.br/listas/2015/07/brasil-e-o-pais-latino-americano-que-mais-investe-emesportes/. Acesso em: 03 out. 2021.

FRANK, André Gunder. El sistema mundial de los 5000 ãnos, 1993.

FRANK, André Gunder. Tigre de papel, dragão de fogo. Aportes, Revista de la Facultad de Economía, BUAP, ano 10, n. 29, mai/ago. 2005.

FREITAS, Ricardo Ferreira Freitas; LINS, Flávio; SANTOS, Maria Helena Carmo dos.

Megaeventos: motores de transformação social. Anais do XXIII Encontro Anual da Compós. Pará, p. 1-17, mai. 2014.

GLOBO ESPORTE. China gastou 447 milhões de dólares só com jogadores brasileiros em cinco anos. Disponível em: https://globoesporte.globo.com/futebol/futebol-internacional/ noticia/china-gastou-447-milhoes-de-dolares-so-com-jogadores-brasileiros-em-cinco-anos.ghtml. Acesso em: 13 dez. de 2019.

GLOBO ESPORTE. Legados esquecidos dez anos depois de Pequim 2008 instalações estão abandonadas. Disponível em: https://ge.globo.com/olimpiadas/noticia/legado-esquecido-dezanos-depois-de-pequim-2008-instalacoes-olimpicas-estao-abandonadas.ghtml. Acesso em: 03 out. 2021. 
A Nova Rota Econômica do Futebol: megaeventos esportivos e "o sonho chinês das três Copas"

KELLNER, Douglas. Cultura da mídia e triunfo do espetáculo. In: MORAES, Dênis de (org.). Sociedade midiatizada. Rio de Janeiro: Mauad, 2006.

MARICATO, Erminia. A copa do mundo e as cidades: políticas, projetos e resistências. In: SÁNCHEZ, Fernanda; BIENENSTEIN, Glauco; OLIVEIRA, Fabrício Leal de; NOVAIS, Pedro (orgs.). Niterói: Editora da UFF, 2014.

MATIAS, WAGNER BARBOSA. A economia política do futebol e o "lugar" do Brasil no mercado-mundo da bola. In: Repositório Unb. https://resources.fifa.com/mm/document/ affederation/generic/02/78/29/07/fifastatutswebes_spanish.pdf. Acesso em: 03 out. 2021.

MEDEIROS, Carlos Aguiar de. A China como um duplo pólo na economia mundial e a recentralização da economia asiática. In.: LIMA, Marcos Costa (org.). Dinâmica do capitalismo pós-guerra fria: cultura tecnológica, espaço e desenvolvimento. São Paulo: Editora UNESP, 2008.

MELO, Victor Andrade de; DRUMOND, Maurício; FORTES, Rafael; SANTOS, João Manuel Casquinha Malaia (orgs.). Pesquisa histórica e história do esporte. Rio de Janeiro: 7 Letras, 2013.

OLIVEIRA, Nelma Gusmão de; VAINER, Carlos. Megaeventos no Brasil e no Rio de Janeiro: uma articulação transescalar na produção da cidade de exceção. In: Anpuh, 2021.

PIZARRO, Juliano Oliveira. FIFA e o soft power do futebol nas relações internacionais. Recorde, Rio de Janeiro, v. 10, n. 2, p. 1-19, jul./dez. 2017.

PRICEW ATERHOUSECOOPERS. 24th Annual Global CEO Survey. In: PWC. Disponível em: https://www.pwc.com/gx/en/ceo-agenda/ceosurvey/2021.html. Acesso em: 13 ago. 2020.

RODRIGUES, Carlos; JÚNIOR, Emanuel Leite. A geopolítica do futebol em transformação: o caso chinês. Revista FuLiA/UFMG, Belo Horizonte, v. 3, n. 2, p. 28-50, mai./ago. 2018.

RODRIGUES, Mariana Ramalho. $O$ poder institucional da FIFA como um ator não estatal na política internacional. 2015. 100 f. Dissertação (Mestrado em Relações Internacionais) Faculdade de Economia, Universidade de Coimbra, Coimbra, 2015.

ROSS, J. Andrew. A Companion to American Sport History.In: RIESS, Steve. . Maden, EUA: Wiley Blackwell, 2014.

SÁNCHEZ, Fernanda; BIENENSTEIN, Glauco; OLIVEIRA, Fabrício Leal de; NOVAIS, Pedro (orgs.). A copa do mundo e as cidades: políticas, projetos e resistências. Niterói: Editora da UFF, 2014.

SANTOS, João. O Monopólio dos Esportes: uma comparação da organização dos esportes comercializáveis nos Estados Unidos, na Inglaterra e no Brasil (1870-1920). História Econômica \& História das Empresas. v. 15, n. 2, 2012, p. 47-80.

SANTOS, Milton. Los espacios de la globalización, 1993.

SCOTT, Peter; WALKER, James; MISCALL, Peter. British working-class household composition, labour supply, and commercial leisure participation during the 1930 's. Economic History Review, v. 68, n. 2, 2015, p. 657-682.

SURDAN, George. Century of the Leisured Masses: Entertainment and the Transformation of Twentieth-Century America. The Economics of Leisure, New York: Oxford University Press, 2015. 
SZYMANSKI, Stefan. Economics and (Modern) Sports History. In: The International Journal of the History of Sport, 2015, v. 32, n. 15, p. 1775-1777.

THE INTERNATIONAL MONETARY FUND. In:IMF. Disponível em: https://www.imf.org/en/ Publications/AREB/Issues/2016/12/31/From-Stabilization-to-Sustainable-Growth. Acesso em: 27 set. 2020.

TSÉ-TUNG, Mao. Obras escolhidas de Mao Tsé-Tung, Pequim, 1975, Tomo I.

UVINHA, Ricardo. Os megaeventos esportivos e seus impactos: o caso das Olimpíadas da China. Motrivivência, ano XXI, no 32/33, p. 104-125, jun./dez. 2009.

XI JINPING. El sueño chino, 2015. 